\title{
Understanding the Sustainable Outcome of Project Delivery Methods in the Built Environment
}

Chi Kwan Fong

California State University Fullerton ckfong@csupomona.edu
DOI 10.5592/otmcj.2014.3.9

Research paper

\section{Keywords}

Project delivery method;

Project outcome; Process execution; Project sustainable outcome; Built environment; process, people, and system

\author{
Hakob Gevorg Avetisyan \\ Department of Civil and Environmental \\ Engineering at California State \\ University Fullerton \\ havetisyan@fullerton.edu
}

\author{
Qingbin Cui \\ Department of Civil and Environmental \\ Engineering at University \\ of Maryland College Park \\ cui@umd.edu
}

IN THE DESIGN AND CONSTRUCTION INDUSTRY, BUILDING OWNERS WANT TO IDENTIFY, CONTROL, AND MITIGATE PROJECT RISKS BY DECIDING ON HOW PROJECTS WILL BE DELIVERED ON TIME AND WITHIN BUDGET. Project delivery method is a comprehensive process by which designers, constructors, and various consultants provide services for design and construction to deliver a complete project to the owner (Migliaccio et al., 2008). This research paper discusses the types and impacts of various project delivery methods that affect project outcome. The purpose is to understand how project stakeholders interact within the delivery method for the best outcome. To analyze the effectiveness of project delivery method, two case studies in the public higher education in California are reviewed. Both projects are delivered under the same project delivery method. The project outcomes varied significantly in terms of cost, schedule, scope compliance, quality, and stakeholders' expectations. These outcome variances in the case studies demonstrate the necessity to understand the benefits of strategic alignment of process execution with the culture of integrative team to produce project sustainable outcome in the built environment. Applying an integrated project delivery method is not a substitute for a high performance team. The interdisciplinary interaction and balancing project constraints (cost, time, and scope) with the integrative nature of 3 core areas (Process, People, and System) will contribute to project success. A project sustainable outcome has positive benefits and long term impacts on the society, economy, and the environment. 


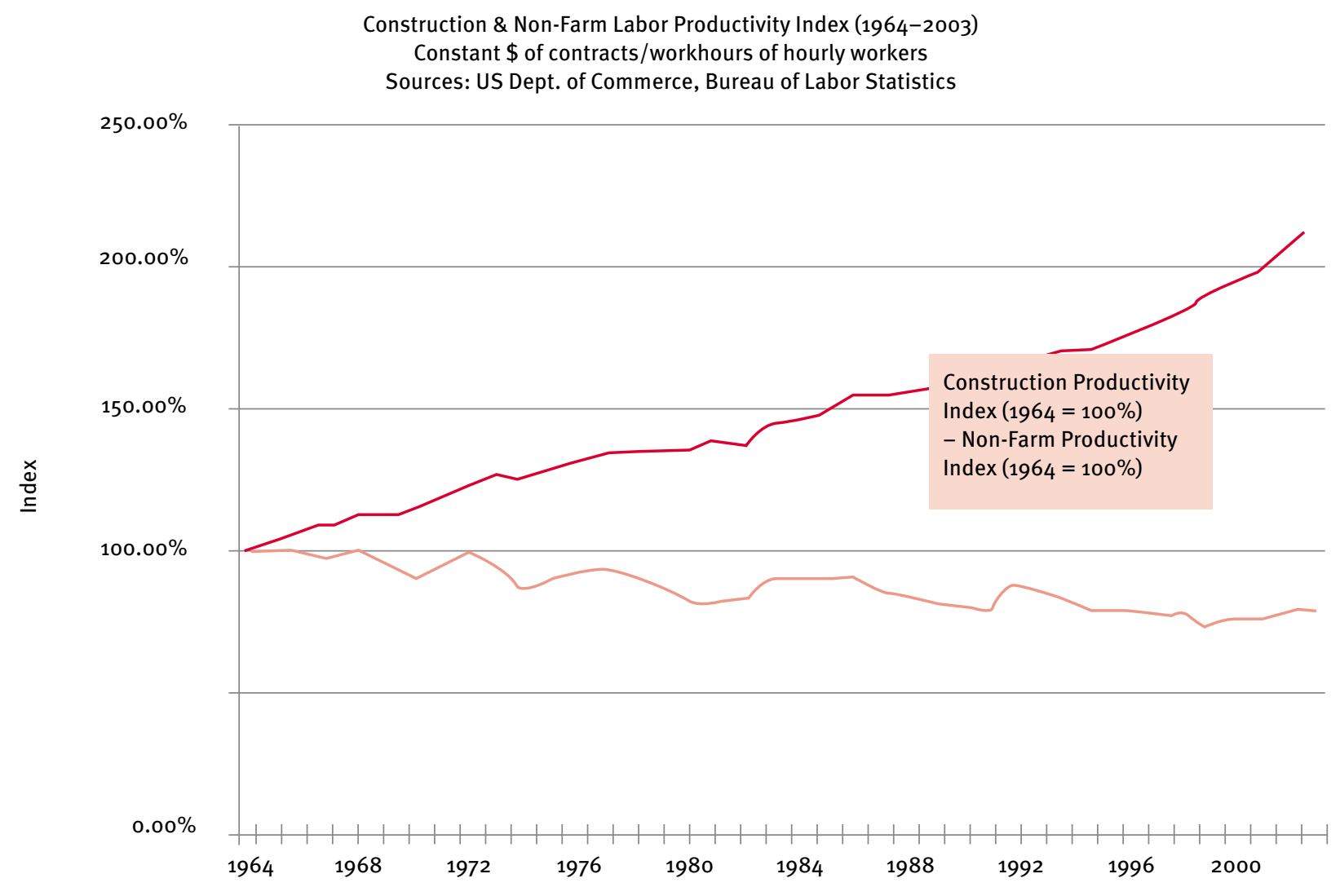

Figure 1 Construction and Non-Farm Labor Index (1964-2003)

Source: U.S. Department of Commerce, Bureau of Labor Statistics

\section{INTRODUCTION}

A project is a temporary endeavor undertaken to create a unique product, service, or a result (Project Management Institute, 2014). Delivery refers to the method for assigning responsibility for providing a service (American Institute of Architects, 2013). A method provides a framework on how the project will be designed and constructed to meet specific project objectives. Project delivery is a form of working relationship that defines roles and responsibilities. Project delivery methods are often selected based on non-quantitative approaches (Oyetunji, 2001). The main criteria for measuring the success of any project delivery methods are cost, quality, time, safety and how the project ultimately meets its intended purpose (American Institute of Architects, 2014). The suitability of the project delivery method selected for a project greatly influences the efficiency with which the project is executed and thus constitutes a critical success factor (Oyetunji and Anderson, 2006). Despite the recent improved information and construction technology, and specialized technical expertise, the construction productivity index has not improved from 1964 to 2003 (United States Bureau of Labor Statistics, 2003) (Figure 1). Quality defects, decreased productivity, and costs of rework are causes of disputes in the construction industry, leading to tense working relationship and low efficiency of the industry (Zaghloul and Hartman, 2003; O'Connor, 2009). Construction projects carry the risks of cost overruns and schedule delays, and the average duration of construction claims rose from 9.1 months to 10.6 months in United States (Jack, 2012).

\section{Project and Construction}

Management for Project Outcome

Project management is the application of knowledge, skills, and techniques to project activities to meet the project expectations and requirements (Project Management Institute, 2014). Construction management is a professional management practice applied to construction projects from project inception to completion for the purpose of controlling time, cost, scope and quality (Construction Management Association of America, 2011a). The maturity in project management processes is strongly associated with a high project success rate (Besner and Hobbs, 2008). Construction management is a delivery method neutral that is productive and valuable in combination with any of the project delivery methods in use today (Construction Management Association of America, 
2011b). In 2011, the Chartered Institute of Buildings in the United Kingdom redefined the meaning of construction management. The re-definition provides an agenda for process improvement and reflects a 21st century view of a profession which is concerned with the entire life-cycle of built assets, with an emphasis on sustainable development (Chartered Institute of Building, 2011). The re-definition focuses on how people interact with the process and the environment that are shaped by seven guiding principles: 1) People professional development; 2) Quality of life; 3) Sustainable future; 4) Ethical practices; 5) Management innovation; 6) Social responsibility; and 7) Emotional success. The re-definition highlights the essential relationship and interaction of process, people, and system for sustainable outcome in the built environment.

Sustainability is an economic state where the demands placed upon the environment by people and commerce can be met without reducing the capacity of the environment to provide for future generations (Hawken, 1993). Project objectives are planned and defined in terms of outputs, outcomes, or benefits (Association of Project Management, 2014). A project output is a deliverable as specified. The project team's roles and responsibilities for meeting these criteria vary by project delivery method. Project output is not a direct measurement of its outcome that is both tangible and intangible. Project outcome is measured by some pre-determined metrics or performance criteria with project constraints including time, scope, cost, and quality compliance (Project Management Body of Knowledge, 2013) (Figure 2). Project outcome is also governed by the degree of stakeholders' satisfaction, expectations, feelings, and perception developed throughout the entire project life cycle. A project has a successful outcome if it achieves the objectives or needs as specified by the acceptance criteria, within an agreed timescale and budget (APM, 2014). Project outcome is the total sum of project constraints management, project barriers reduction through a delivery method. Value is generated when project needs are fulfilled.

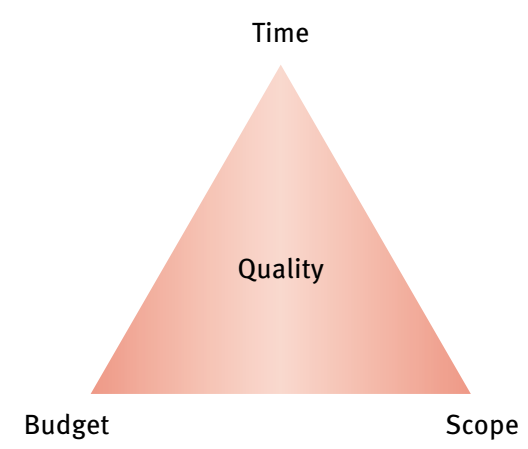

Figure 2 Project constraints Time, Budget, Scope, and Quality Source Project Management Body of Knowledge, Fifth Edition, 2013

\section{Project delivery methods}

There is no one perfect delivery method for every project. Project delivery method is one of the six project delivery attributes (Korkmaz, 2007) for project success. The six attributes include: 1) Project delivery method; 2) Owner's commitment; 3) Project team procurement; 4) Contractual provisions; 5) Level of integration in the design process; and 6) Project team characteristics. Project's characteristics influence the decision making process on selecting the right project delivery method. Project's characteristics include the size and complexity, funding source, schedule expectation, design and scope requirements, internal staff capabilities, and the level of acceptable financial and legal risks (Association of California Construction Managers, 2011). Project planners and managers make various assumptions with respect to execution of construction activities, availability of resources, suitability of construction methods, and status of preceding activities (Gao et al.,
2013). Decisions made based on invalid assumptions can negatively impact the outcomes of construction projects, such as rework, activity delays, and extra material cost (Ballard 1999; Thomas et al., 2003). Project delivery methods involve relationships of project stakeholders; and their timing of engagement in the project, regardless of the tools and processes used (Sanvido and Konchar, 1998).

Types of Project Delivery Methods Project delivery methods define the contractual relations, timing of involvement of project participants, and contract conditions such as penalties, incentives, risks, and liabilities (Charles Pankow Foundation, 2010). Risk tolerance is the extent to which an organization chooses to risk experiencing a less favorable outcome in the pursuit of a more favorable outcome (International Standards Organization, 2012). Understanding the characteristics of different project delivery methods helps building owners make informed decisions on the selection process to understand and address specific project risk tolerances.

There are three primary construction project delivery methods in the United States: Design-Bid-Build (DBB), Construction Manager at Risk (CMR), and Design-Bid (DB) (Construction Management Association of America, 2012). The Design-bid-build (DBB)'s market share for non-residential projects has decreased from $65 \%$ to $58 \%$ from 2005 to 2012 (Design-build Institute of America, 2013). Also, the same report shows that the market share of the Design-bid (DB) and Construction Manager at Risk (CMR) has increased from $33 \%$ to $43 \%$ (Figure 3). The increased industry's acceptance and application of the DB and CMR project delivery methods suggest that the market has matured or shifted to address building owners' expectations on reduced risks and on project team collaboration and integration in the 
Project Delivery Market Share for Non-Residenital Construction

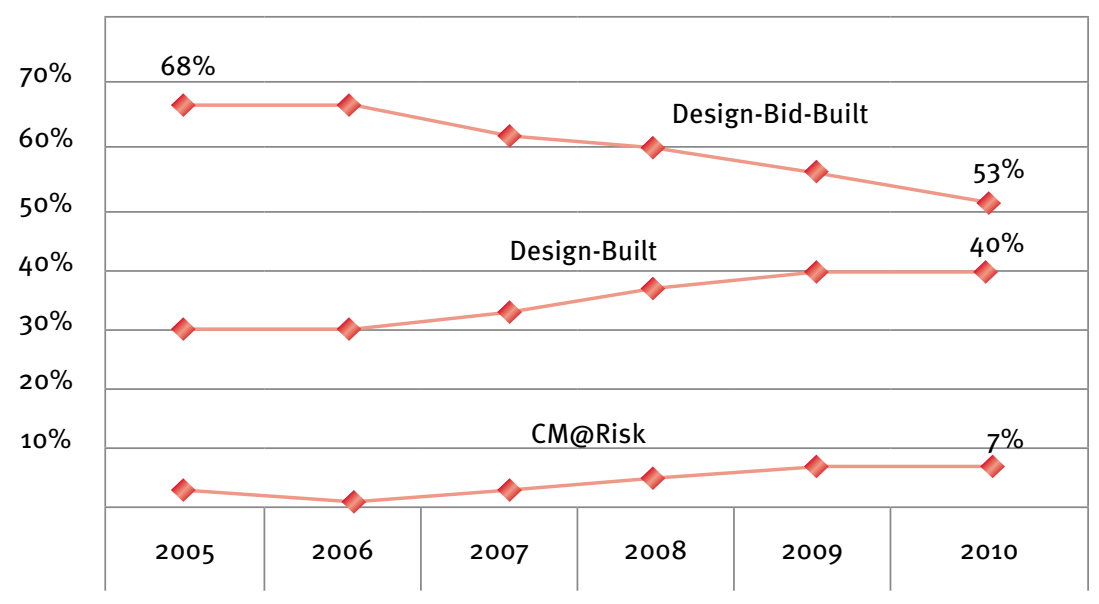

Figure 3 Project Delivery System Market Share

Source: Reed Construction Date / RS Means Market Intelligence Report, Design-build Institute of America, 2013

early design phase. The popularity of one project delivery method does not necessarily translate into credibility nor do any of these project delivery methods guarantee project success.

\section{Design-bid-build (DBB)}

DBB remains a prevalent delivery model in the United States' construction industry because it provides the building owner the market advantage of open competition through a separate design and construction contract (American Institute of Architects, 2007). Primary parties are the building owner, the designer, and the general contractor. DBB separates the project delivery process into design, bid, and construction phases in a linear manner (Construction Management Association

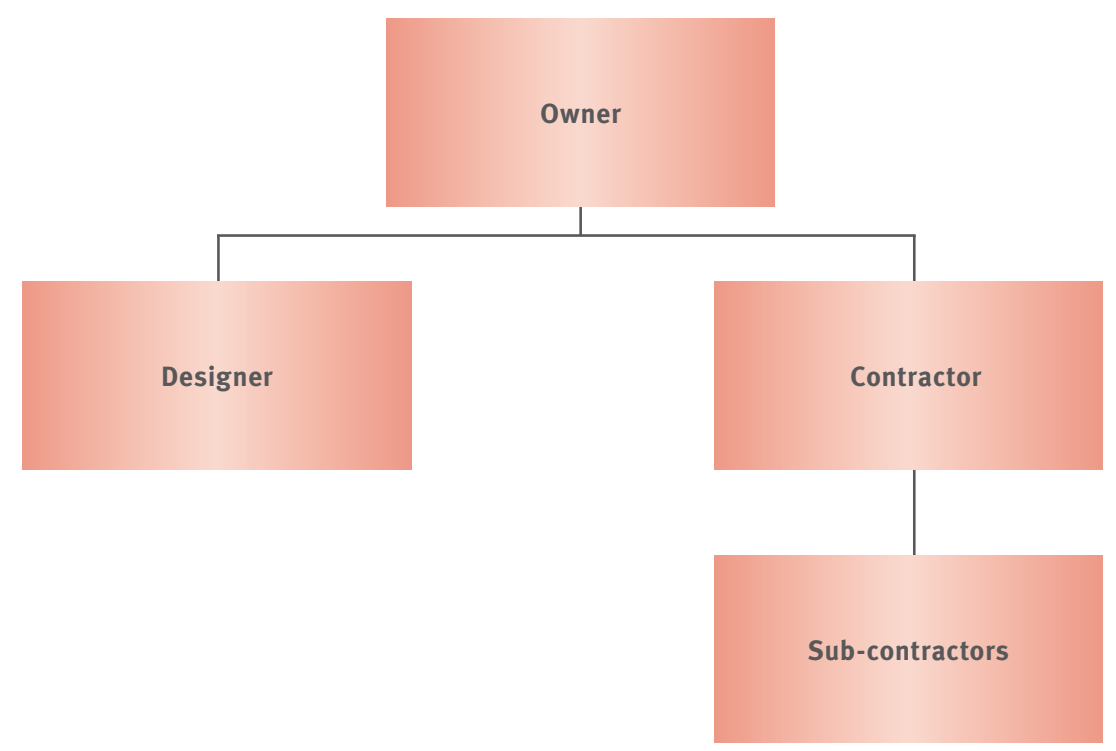

Figure 4 Design-bid-build (DBB)

Source: Construction Management Association of America 2012

of America, 2012). There is no direct involvement and integration between the designer and general contractor in the design phase. During the design phase, the building owner engages a qualified design firm to prepare the design documents of the project. Once the design phase is completed, the bid package is advertised for prospective qualified bidders. A general contractor is then procured through a competitive bidding process. The selected general contractor is responsible to construct and deliver the project within a specified timeframe and for a specified price (Figure 4).

\section{Assumptions.}

The DBB model assumes that the design is well managed to meet the budget and the lowest competitive bid price is always within the construction budget. The assumption is based on the accurate project cost estimations prepared during the design phase. The designer is responsible for coordinating and completing the design documents to meet the budgetary, time, scope, safety, and quality requirements. The completeness of the design documents relies on the design team's coordination abilities, competency, and experiences.

\section{Advantages.}

The DBB model is well understood in the design and construction industry. The roles and responsibilities are clearly defined for all parties involved in the contracts. The building owner manages the overall project process and controls the scope with technical support and design coordination from the designer. The building features are determined, developed, and specified to meet the budget. The building owner can benefit from open price competition particularly in a weak construction economy with high unemployment rate. Substantial cost savings may be realized if the lowest competitive bid falls below construction budget. 


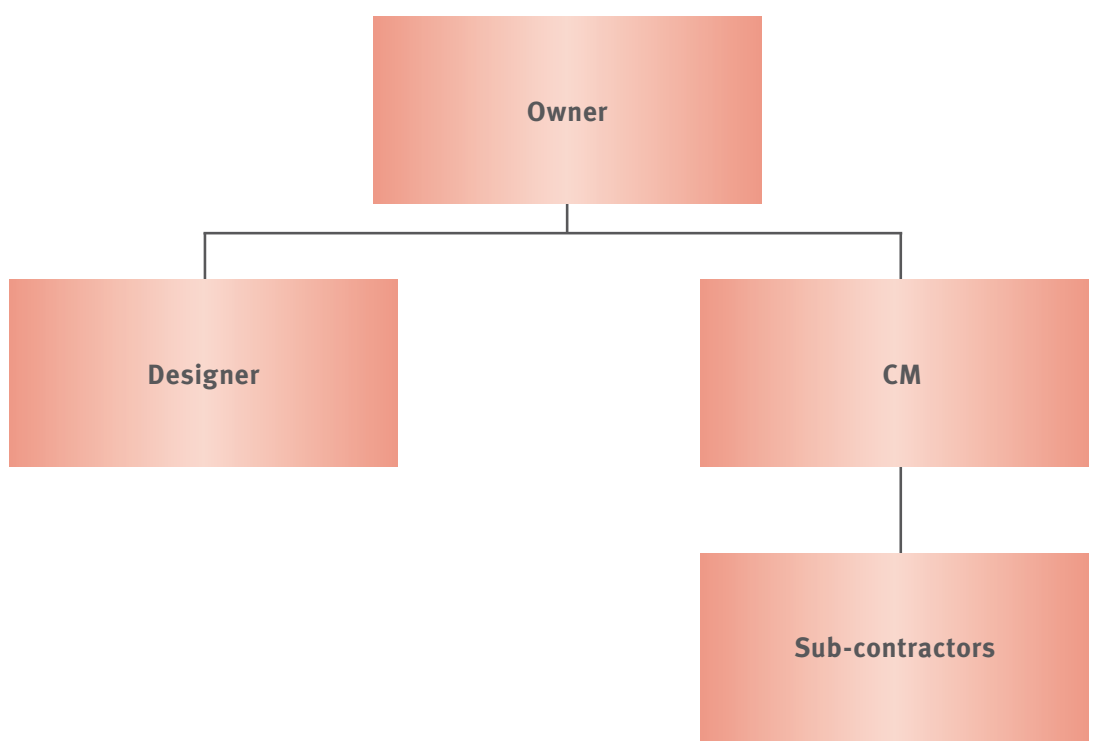

Figure 5 Construction Manager at Risk (CMR)

Source: Construction Management Association of America 2012

\section{Disadvantages.}

The linear nature of the DBB model is time-consuming and resources extensive because all design work must be completed prior to the bid solicitation and construction phases. The linear process can be disrupted by any major uncontrolled risks and uncertainties due to the ever-changing bidding climate in the industry. With limited funding and complex procurement procedures, some public building owners are more vulnerable to the process disruption and bid cost overruns. The absence of qualified general contractor's input in the early design phase will limit the completeness of constructability of the design documents. The DBB model promotes adversarial project relationships because there are limited or no previously established working relationships among the building owner, designer, and the contractor (Construction Management Association of America, 2014). Because the selected contractor is usually the lowest-bidder, there is a tendency for the selected contractor to solicit potential claim opportunities over design errors or omissions to recover costs during construction. Building owners are exposed to potential construction disputes that further disrupt the project progress.

Construction Manager at Risk (CMR). Under the CMR model, the building owner engages a Construction Management (CM) firm for team integration with the designer early in the design phase called pre-construction phase. The CM firm plays two different contractual roles: acting as a construction and cost consultant to the owner in the pre-construction phase, but as a general contractor during the construction phase upon agreement of the construction contract sum (Construction Management Association of America, 2012). During the pre-construction phase, the $C M$ firm provides advisory professional management assistance to the building owner on schedule, budget, and constructability as the project makes progress on design development phase (Figure 5). The CM firm manages the project for the purposes of delivering early cost commitment and to manage issues of construction and building technology of the project (American Institute of Architects, 2007). The CMR model builds on the development of early working relationship and sharing of design and construction knowledge in early design phase. The selection of Construction Management (CM) firm is based on the technical qualifications and the proven track records of the proposed team and the building owner's trust that they will perform as expected.

\section{Assumptions.}

The CM firm is at risk, not the building owner as the name: CMR implies. The CM firm provides effective cost control and constructability reviews on the design documents prepared by the designer during the pre-construction phase. The designer is responsible for providing the standard of care on design and technical coordination. The designer provides limited construction oversight during construction phase. The CM firm warrants the completeness of the design documents prior to becoming a general contractor upon the award of construction contract. The CM firm will pay for the redesign if the bid price exceeds a certain percentage of the predetermined construction budget.

\section{Advantages.}

The CMR model allows for early development and promotion of effective project team building and working relationship. The CM firm's constructability inputs enhance the quality and build-ability of design documents. The building owner has less exposure to bid cost insecurity because of the CM's intention to guarantee the construction cost prior to the start of bid phase.

\section{Disadvantages.}

The building owner is at risk because any project risks transferred to the CM firm are not without impacts to the project scope, quality, and schedule. The CM firm converts from the advisory role of a construction manager in the pre-construction phase to the contractual role of a general contractor in the construction phase. There are no longer implied duties of loyalty and care 


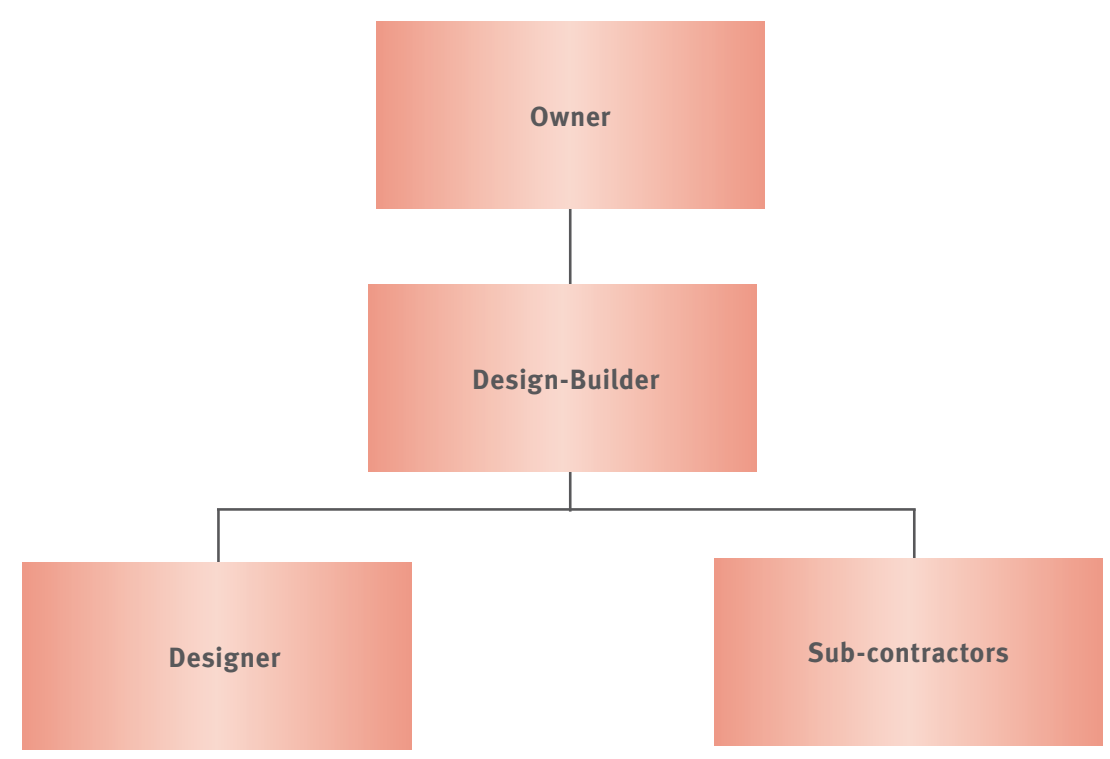

Figure 6 Design-build (DB)

Source: Design-build Institute of America 2014

to the building owner in the construction phase (Construction Management Association of America, 2014). The CM firm has no legal control on how the trades bid the project. The integrated relationship in the pre-construction phase will not guarantee the same cooperative construction management process. Potential conflicts or disputes over design errors, construction defects, and liabilities on work performed may occur. Tension grows over construction cost overruns and delays will put the project at greater risk.

\section{Design-build (DB).}

The DB model is an alternative project delivery method in which one entity: the design-build team, works under a single contract with the building owner to provide overall design and construction service (Design-Build Institute of America, 2014). The building owner contracts with a single design-build team to plan, implement, and control the entire project through completion and occupancy (Construction Management Association of America, 2011). The BD model not only allows for team integration early in the project design phase (Figure 6), but also

\section{Disadvantages.}

The building owner has limited control or influence on the final design quality since the designer is not contracted directly with the building owner. The design criteria are mostly cost-driven in the context of quality and scope in the early design phase. It is difficult for the building owner to verify if the project has achieved the best value or performance criteria throughout the design process.

\section{Process, people, and system (pps)}

the concept of the "triple bottom line - People, Planet, and Profit" measures organizational success that goes beyond the traditional bottom line which only assesses profitability. The triple bottom line accounts for an organizations ecological, social performance, and financial performance (Elkington, 1994). Value management or value improving practices provide an organized approach to minimize life-cycle costs while optimizing the life of a facility (Construction Industry Institute, 2014). Project team interactions contribute to the fulfilment of needs (Lapinski et al., 2006). Project outcome encompasses expectations on project success on project management process, stakeholder participation, and product (building) success. They are translated to and identified as the 3 dimensions of project success

\section{Advantages.}

The building owner has a single point of responsibility with the design-builder firm. Under the DB model, the building owner can start the project with relative little performance criteria or information because it allows full design and construction expertise integration in the design phase. Project risks on cost, scope, and schedule are identified, shared, and mitigated during the design phase. It reduces overall project duration and the potential exposure to complex claims to building owner during construction.

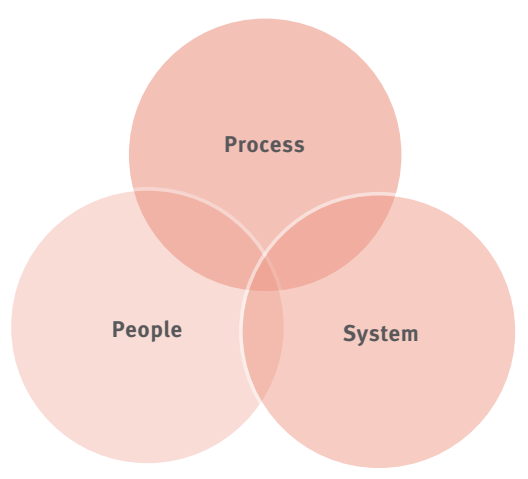

Figure 7 Process, People, and System 
on Process, People, and System (PPS) respectively (Figure 7). The core components of Process, People, and System (PPS) are Coordination, Implementation, and Alignment (CIA) respectively. The $\mathrm{CIA}$ interfaced areas produce the best opportunity available for achieving the sustainable outcome of a project.

\section{Process - Coordination}

The Process defines how the project phases are managed and resources are consumed for desired efficiency and results. Project delivery methods define the roles and responsibilities of parties involved in a project (Oyetunji and Anderson, 2006). The building owner, designer and CM firm are required to recognize the interface and limitations of roles and responsibilities in the process as a project delivery method.

Coordination is a core component of the Process that refers to the method that delivers the project or product outcome. Process involves the elements of 5 management process groups including initiation, planning, execution, monitor/control, and closing activities (Project Management Body of Knowledge, 2013). Process includes stakeholders' work tasks that define and separate the contractual roles of designer and constructor on "coordination by design" and "coordination by construction" respectively. Consequently, efficiency is the sustainable outcome of Process - Coordination.

\section{People - Implementation}

People are stakeholders engaged in partnering and integration through skills and competency. People initiate, form, interact, and develop relationships in a project. People are stakeholders including project sponsors, project team members, vendors, and building users and operators. Team integration is a function of the contractual relationships established in the project (American Institute of
Architects, 2009). Interdisciplinary interactions in early involvement of project participants, levels and methods of communications, and compatibility within project teams result in better outcomes (Lapinski et al., 2006; Enache-Pommer and Horman, 2009; Korkmaz et al., 2007).

Implementation is a core component of People. People refer to human implementation that produces project and product outcome. An improved and healthy project team experiences will also build the working relationships, promote team performance, and enhance emotions of enjoyment. Project success is measured by the degree of stakeholders' positive experiences and well-being, during and after the project implementation. Consequently, satisfaction is the sustainable outcome of People - Implementation.

\section{System - Alignment}

The System provides the framework of societal, economic, and enterprise for compliance and strategic effectiveness. Economy provides opportunities for profitability, prosperity, and growth. Economy drives business decisions on capital improvements and investment behaviors. A weak economy reduces spending that funds construction activities although public building owners may prefer a weaker economy as a buyer's market. Enterprise consists of business structure and culture in an organization. Structure controls how projects are managed to meet the corporation's business and strategic goals. Construction projects also provide economic stimulus that may provide a social value as a built environment. Organization culture defines and allows how people behave, interact, and make decisions.

Alignment is a core component of the System. System refers to a framework of external forces or influences by society, economy, and enterprise. Society provides a legal compliance framework for building code or regulations to protect public health, well-being, and safety. Process requires project team's understanding and conformance to the professional code of conduct, and ethical responsibility in the society. Integrity, accountancy, social justice, and public trust are examples of values that influence an organization's vision, mission, and project goals. The four steps of social responsibility include economic, legal, ethical, and philanthropic (Caroll, 1991). Ethical decisions occur when accepted industry standards, principles, rules or regulations no longer serve and decision makers must weigh values and reach a judgment. Alignment provides the condition where appropriate project participants are working within acceptable tolerances to develop and meet a uniformly defined and understood set of project objectives (Construction Industry Institute, 2014). Alignment becomes the necessary condition to ensure that ethical culture serves to address and strategically resolve issues on process effectiveness, people experiences, profitability, and social responsibility. Consequently, ethics is the sustainable outcome of the System - Alignment.

\section{Case studies}

To analyze the effectiveness of a project delivery method for sustainable outcome, two case studies on CMR project delivery system in the public higher education within the California State University (CSU) System are reviewed. The California State University Chancellor's Office is responsible for carrying out the authority of the CSU Board of Trustees in the construction and physical development (CSU Chancellor's Office, 2014). The CMR project delivery method is one of the methods of procuring construction of a public works project within the CSU system. The CMR model is governed under the Contract General Conditions (CGC) with Guaranteed Maximum Price (GMP) Projects (CSU Capital Planning, 
Design and Construction, 2013). The Guaranteed Maximum Price (GMP) is the Not-to-Exceed Contract Amount and it is "the maximum price that the Trustees and Construction Manager (CM) agree upon as payment for managing, providing and installing all the Work" (CSU Request for Proposal CMR, 2013). The $C M$ firm is responsible for cost estimates, systems engineering, and project life cycle analysis (CSU Request for Proposal (MR 2013). The $\mathrm{CM}$ firm is required to perform periodic constructability reviews during the pre-construction phase. The design team is responsible for the technical design or interruption of the design documents (CSU Request for Proposal $C M R$, 2005). The CM firm reviews the design team's construction documents for completeness, coordination, and clarity. By reaching agreement on the Guaranteed Maximum Price (GMP) with the CSU, the CM firm agrees that it has reviewed the construction documents and verified their adequacy and completeness for constructing the project (CMR, 2013). Before solicitation trade bids, the CM firm issues the constructability review warranty letter confirming the completeness of the construction documents (CMR, 2013) prior to bidding. Both case studies are new major capital projects that are located at the California State Polytechnic University, Pomona campus. Case study \#1 is a completed project and case study \#2 is a project in bid phase. During the design phase, both projects experienced budgetary and external economic challenges. Although both projects are delivered under the same CMR model, their project outcomes varied significantly in terms of cost, schedule, scope compliance, quality, and stakeholders' expectations. The projects' data, details, and information were obtained from the Facilities Planning Design and Construction at California State Polytechnic University, Pomona campus.

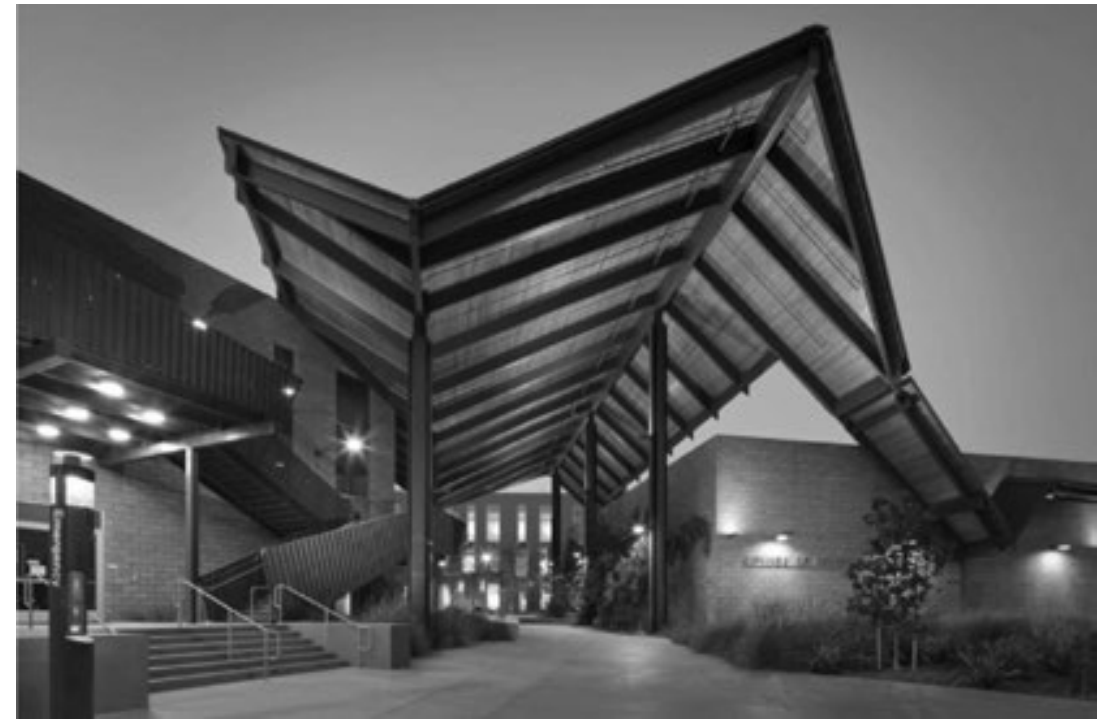

Figure 8 Canopy Entrance, College of Business Administration Photo Credit: AC Martin \& Partners 2014
Case Study \#1 - College of Business Administration Administration complex was completed in 2012. The new complex was needed to maintain and sustain the College's increasing population of 5,000 students. The project is state-funded and it consists of approximately 75,000 SF of new construction for academic and
The \$33M College of Business instructional spaces. The complex has three separate buildings with a dynamic 'folding' roof canopy as the signature entrance (Figure 8). The collective use of materials of copper, wood, and painted metal give warmth to the neutral palette of the other structures and work well with the existing native landscape and surrounding site. Enclosed by the three buildings, the outdoor courtyard serves

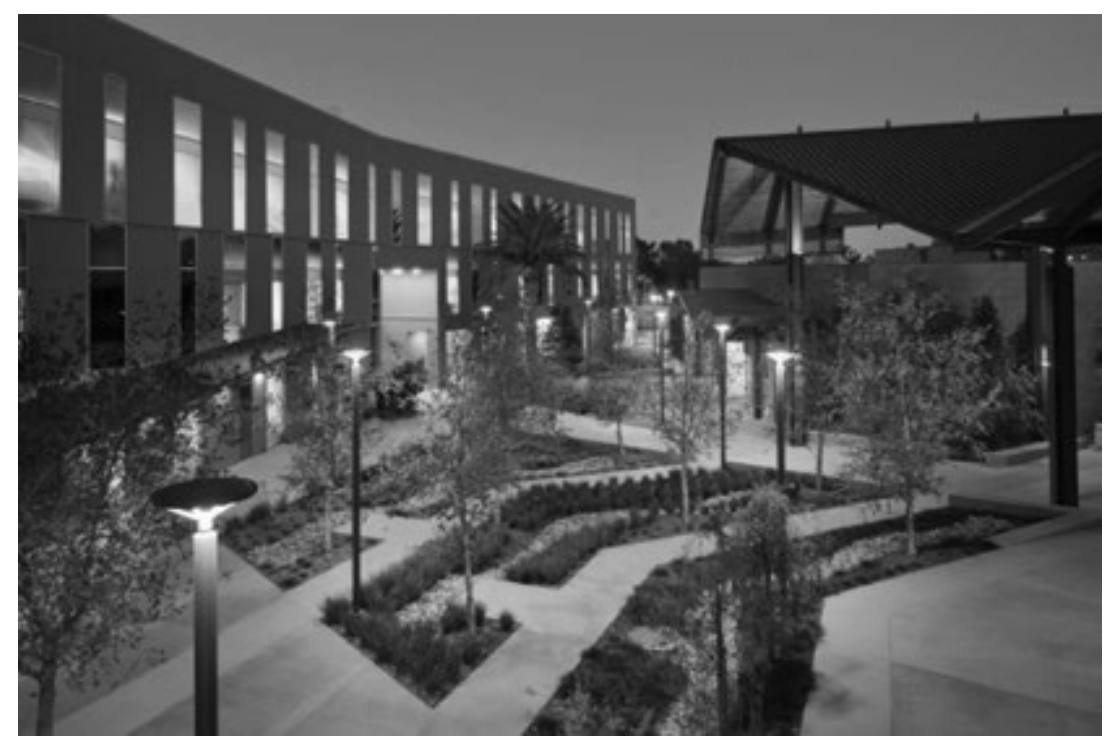

Figure 9 Courtyard, College of Business Administration

Photo Credit: AC Martin \& Partners 2014 
as a social gathering space and provides a sense of community and identity for the College (Figure 9). The complex has been certified Leadership in Energy and Environmental Design (LEED) Silver by the United States Green Building Council (AC Martin Partners, 2012). LEED is a green building voluntary certification program that recognizes best-in-class building strategies and practices (United States Green Building Council, 2014).

\section{Challenges}

During the period of $2005-2007$, the project underwent one of the most economic fluctuations in the United States. The labor and material prices skyrocketed during the housing and construction boom. Prior to the bid phase in 2007, the bid documents cost estimate had a \$3M cost overrun. The 3-story signature entrance canopy was estimated at a construction cost of $\$ 770,000$. The canopy was deleted as a cost saving measure to keep the project within the construction budget of $\$ 33 M$. In 2008 , the national financial crisis and construction meltdown finally came to reality. The project's bidding phase was officially suspended due to the lack of state funding. The changing economic and bidding conditions had disrupted the entire project bid phase and construction start date of 2008.

\section{Economic and Bidding Climates}

The project delay created a new opportunity for team integration and continuous improvement under the CMR model. The contracts with the design and CM firms were not terminated with a mutual agreement that the project will resume when state funding became available. It was beneficial for the project team to maintain continuous and open communications during the suspension period. With additional constructability reviews and cost estimate updates from the CM firm, the design team further enhanced the

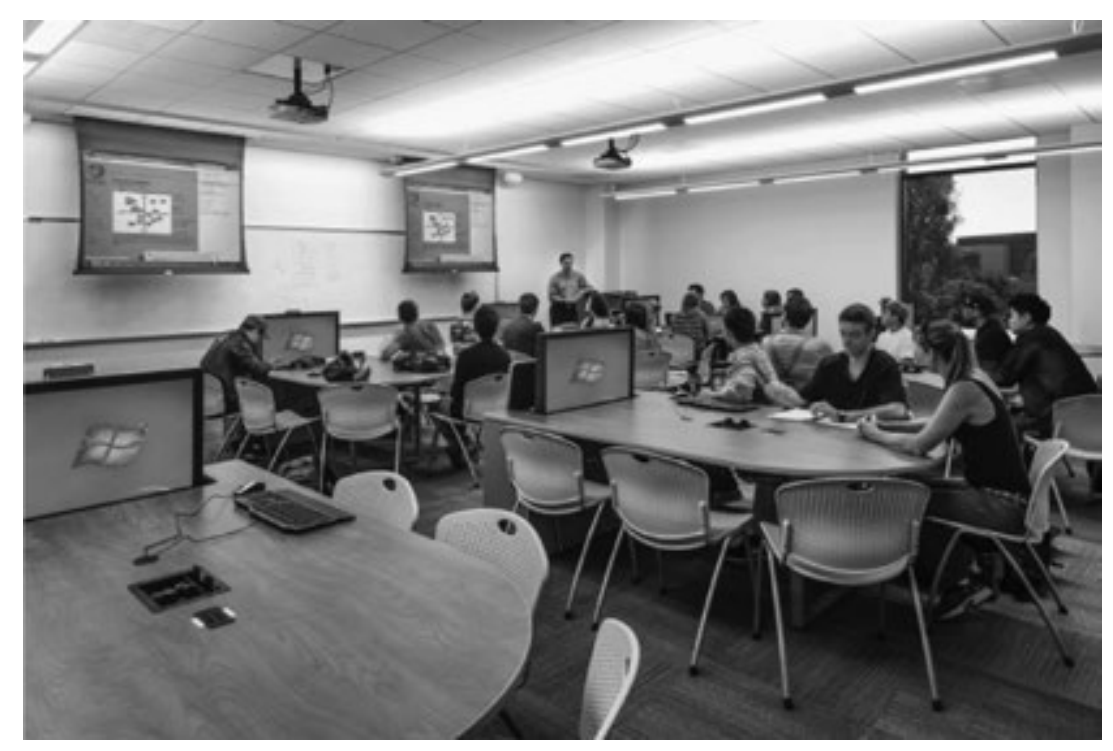

Figure 10 Active-Learning Classroom, College of Business Administration Photo Credit: AC Martin \& Partners 2014

design coordination. In anticipation of future available state funding, some sustainable design features and the entry canopy were added back in the project scope. It was predicted with confidence that the project would have cost less to build, if it were allowed to bid in a near future because of the weak economy. In 2010, the economy stabilized and some state bonds were issued successfully. The project's bidding phase was allowed to resume and official bid results were opened in early 2010. The positive bid result of $\$ 31.2 \mathrm{M}$ confirmed the team's prediction of the competitive market price in a recovering economy. The CMP construction contract was awarded with a returned saving of $\$ 1.8 \mathrm{M}$ to the Building Owner.

\section{Constructability Review}

Constructability review is a major component of CMR process during the pre-construction phase. Under the CMR contract, the CM firm can request in writing an interpretation, clarification, or additional detailed instructions from the designer in case of design errors and omissions (CSU CMR, 2013). During the construction phase, the CM firm raised concerns on the building exterior's water proofing details and their performance through a request for interpretation process. The designer had not admitted the details were not adequately detailed, but agreed to the revision of the water proofing details to enhance the performance as intended. The CM firm argued that because they are not licensed design professionals and therefore are not liable for any additional costs incurred by correcting design details errors. The designer claimed that the CM firm is held responsible and is accountable for all design components reviewed for constructability purposes during the pre-construction phase.

\section{Project Outcome}

In February of 2012, the project was completed and was delivered on time with an additional project saving of $\$ 1 M$. The additional project saving was shared by the CM firm and the building owner. Despite the economic and bidding climate challenges, the CMR model has promised to deliver sustainable outcome in terms of cost, quality, and scope in a cooperative and integrative manner. The entrance canopy has become a campus architectural landmark and signature for the College. The courtyard has added academic pride 
and social value to the campus community. The instructional technologyenhanced active learning classrooms have enhanced student learning outcome because the teacher is more likely to move around and more likely to consult with individuals and groups during lectures (Brooks, 2012) (Figure 10). The project has demonstrated the value of collaborative working relationships as defined by Process, People, and System, despite some disagreement on contractual roles and responsibilities. The CM firm later won two additional capital projects on the same campus due to good working relationships and proven successful track records on CMR delivery method.

\section{Case Study \#1 Analysis}

Under the CMR model, the CM assumes the responsibility for the completeness and constructability of the design documents, eliminating any claims that may arise from ambiguities or conflicts in the design (CSU CMR Request for Proposal 2013). Because there is no perfect set of design documents, both the design and CM firms can make errors and/or omissions during the design coordination and construction review processes. A constructability review has not completely eliminated the CM's potential claims on the design omissions or errors found during construction phase. The level of effectiveness of the CM's constructability review is limited because there are no direct sub-trade inputs during the design phase. The current CMR's languages on CM's constructability review responsibility on design documents for "completeness, coordination, and clarity" are not entirely defensible because they are subject to technical interpretations and debates depending on the extent of design errors and the magnitude of construction cost impacts. The constructability review is one of the CM firm's core responsibilities under the CMR model. The debate on design errors will affect or damage the collaborative approach under the partnering spirit of CMR model. All ambiguities contract languages should be clarified, redefined or modified to minimize CM's claims on design errors. Three strategic options are proposed to address the challenges.

\section{Strategic Option 1:}

Defining Coordination by Design and Coordination by Construction

Project team members coordinate to develop and complete the design documents. Design omissions or coordination conflicts are not avoidable. "Coordination by Design" and "Coordination by Construction" are two specific portions of project coordination activities. The design team is liable for the design and is therefore responsible for the portion on Coordination by Design. The contractor is responsible for field construction sequences, means and methods, and construction logistics to deliver the project in accordance with the design documents. Therefore the contractor is responsible for the portion on Coordination by Construction. CM's constructability review ensures the effectiveness of coordination by design through the perspective of construction in the pre-construction phase. The constructability review is reactive and linear in nature because they are usually performed when design details are sufficiently coordinated and developed in the design phase. Constructability review should re-focus on predicting the design impact on the degree of cost, schedule, and life-cycle assessment before the details are fully developed and priced in the cost estimates. The format and level of details on conducting effective constructability review should be further explored and integrated into the quality of decision making on the Process, People, and System. The constructability review format should be compatible and shared with the design team's internal quality assurance management plan during the designer's process on the Coordination by Design. The purpose is to achieve a clear responsibility on the consequences on Coordination by Design and Construction.

\section{Strategic Option \#2: Articulating Contracting Compatibility}

The designer is responsible for the correctness and design completeness of the technical design of the project, and the technical interpretation of design issues (CSU CMR Request for Proposal 2013). The designer is responsible and is held accountable for any design ambiguities or conflicts when the design documents are not reasonably coordinated. This contractual requirement should be shared and agreed by both the design and CM teams in their respective contracts with the building owner. There should be direct linkage between the design and CM teams regarding how the shared responsibilities and consequences of constructability reviews will be confronted and negotiated during the preconstruction and construction phases. Contractual languages applicable to both design and CM teams in terms of coordination responsibilities and necessary actions to address construction issues as a result of their professional negligence should be clearly articulated. For example, the design team is entirely responsible for all design intentions that shall be communicated and coordinated clearly on the design documents regardless of the completeness of CM's constructability review. The purpose is to reiterate the design team's legal responsibility and liability on quality design, standard of care, and the Design by Coordination efforts. Similarity, the CM firm is required to provide design-assist (not statutory code reviews) during the pre-construction phase by actively participating in all design coordination meetings. CM's comments and recommendations are recorded for design feedback to validate the project's progress and 


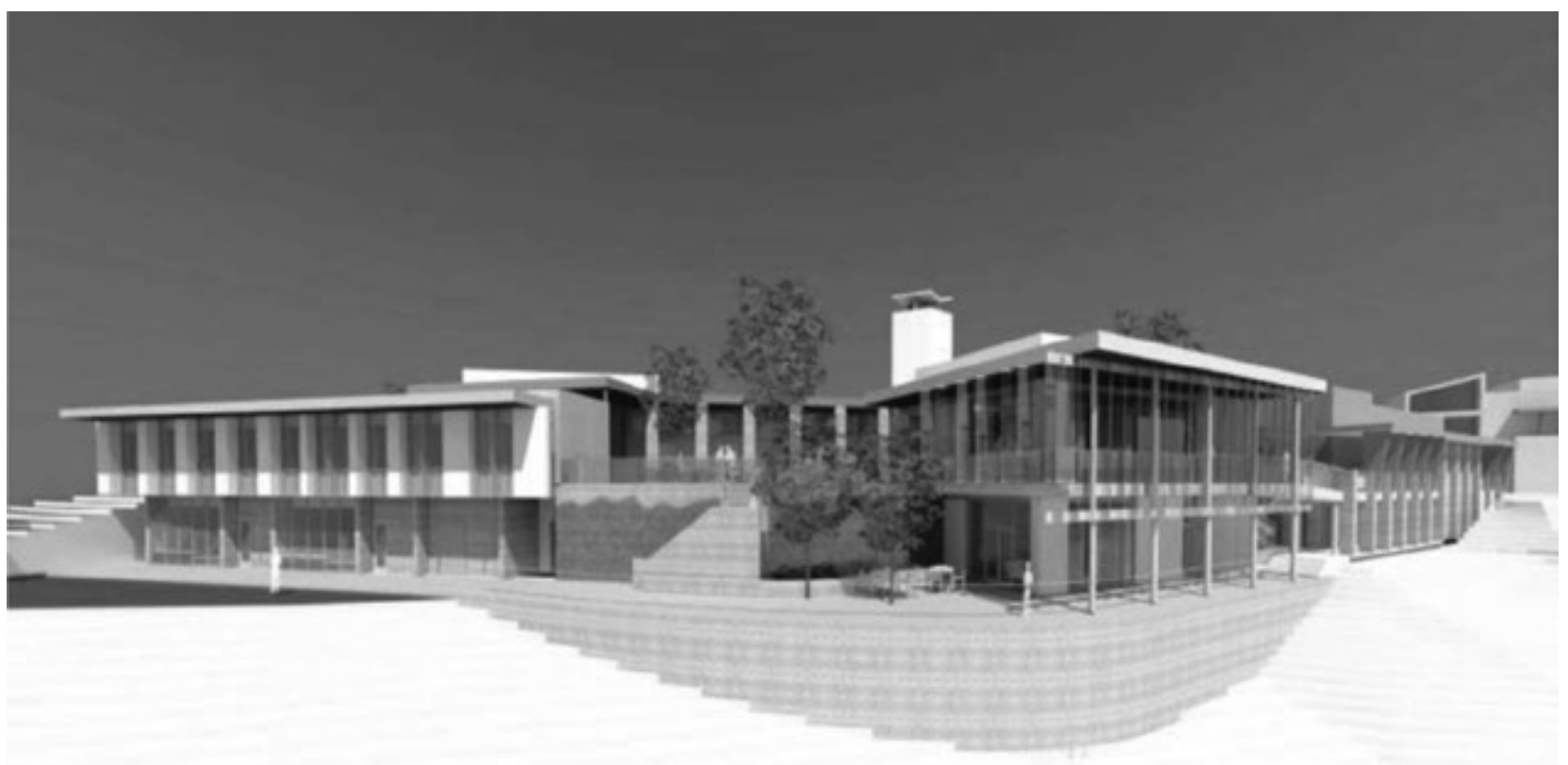

Figure 11 Architect's rendering showing early design concept falls within the $\mathbf{\$ 7 . 8} \mathbf{M}$ budget

Source: HMC Architects, Collins College of Hospitality and Management 2013

benefits on cost, quality, and time savings. This will legitimatize the sense of ownership, accountability, and confidence on the CM's constructability review warranty letter as required under the CMR model.

\section{Strategic Option 3: Applying the}

\section{Spirit of Partnering}

Partnering motivates collaboration throughout the design and construction phases. Partnering embodies the contractual and behavioral principles such as mutual respect, trust, willingness to collaborate, and open communications (American Institute of Architects 2014). The spirit of partnering can be applied to the project team as a day-to-day value adding strategy to assess its effectiveness as a process that determines the outcome. The role of the building owner is also critical in promoting and applying the spirit of partnering under the CMR model. The building owner can use effective project management skills and organizational strategies to successfully deliver a project through continuous partnering. The spirit of partnering provides opportunities for building owner to exercise judgment and to use discretion to support the project team.

\section{Case Study \# 2 - College of} Hospitality and Management Expansion Project

With a construction budget of $\$ 7.8 \mathrm{M}$, the project is funded by private donors. The project is designed to be built on an existing hillside adjacent to a privately owned parking lot. Project program calls for two separate buildings with approximately 15,000 SF of academic and student commons spaces. The project has been designed to achieve LEED Gold certification. Construction has been scheduled to start in early 2014 with construction duration of 18 months for Fall quarter occupancy in 2015.

\section{Challenges}

The project design phase started in early 2012. The preliminary design phase cost estimate was within the construction budget of $\$ 7.8 \mathrm{M}$ (Figure 11).
However, subsequent cost estimates showed cost overruns of $15-25 \%$ as the project moved forward to detailed design phase through 2013. The cost overruns were unexpected because the program design and engineering scope had not been increased or altered. The building owner and the project team decided to simplify the design, reduced the site development, deleted the proposed cool tower, and other non-essential building features. The final bid documents cost estimate was reconciled to meet the budget of $\$ 7.8 \mathrm{M}$ in late 2013 .

\section{Economic and Bidding Climates}

Official bids were opened in January of 2014 with a surprising cost overrun of $\$ 2.3 \mathrm{M}$ (Figure 12). When faced with unfavorable bid results in construction industry, building owners generally have a few options: 1 ) Withdrawing the bid; 2) Increasing funding to cover the bid cost overrun; 3) Reducing the scope to meet the construction budget, or 4 ) Terminating the project. In a moderate economic condition and bidding 


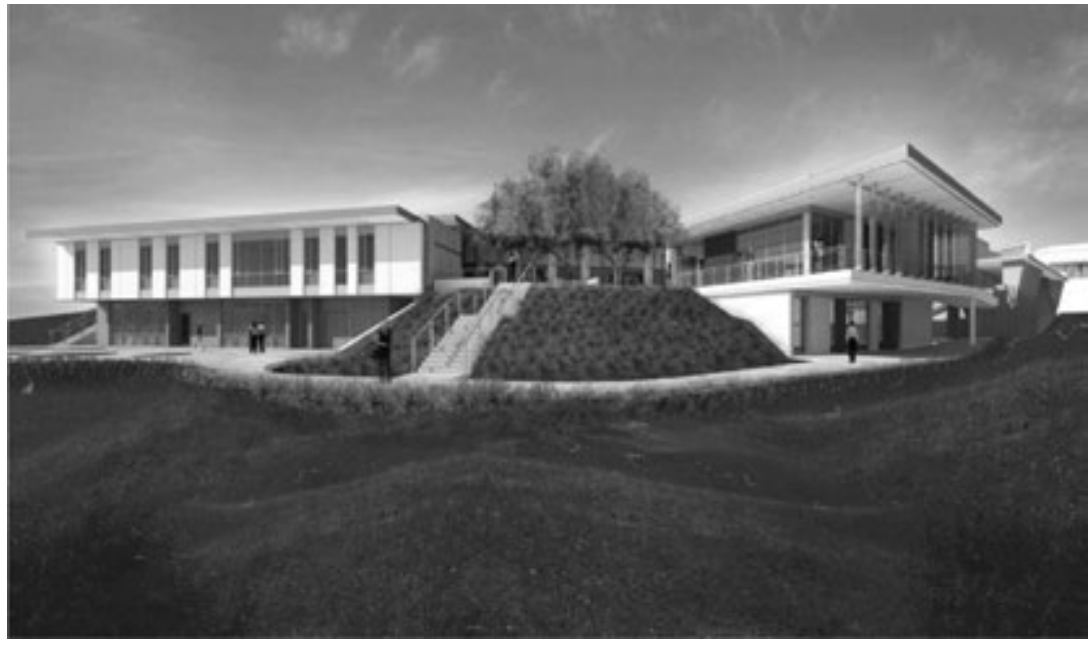

Figure 12 Architect's rendering showing end of bid phase with \$2.3M cost overrun Source: HMC Architects, Collins College of Hospitality and Management 2013

market of $\mathbf{2 0 1 4}$, it is uncommon that the final bid documents reconciled cost estimates showed a significant cost overrun of $\$ 2.3 \mathrm{M}$ (28\% over the $\$ 7.8 \mathrm{M}$ construction budget) under the CMR model.

\section{IPredicting Project Outcome}

The CMR model allows for bid cost overrun variation of $5 \%$ that will require the CM firm to value engineer the project and rebid as necessary (CSU Request for Proposal CMR, 2013). The building owner has the option to request that the CM firm pays the design team to re-design the project to meet the construction budget at no additional cost to the building owner. However, the current CMR model has not provided the building owner with other contingency plans and mitigation measures in terms of project controls on schedule and cost recovery. Careful comparative analysis is needed to explore the advantages and disadvantages of possible strategic options based on the impacts to the project outcome from the Process, People, and System perspectives. Strategic options are needed to manage expectations and predictions on project outcome.

\section{Case Study \#2 Analysis}

The objectives of the analysis are to identify the key project considerations, prioritize project requirements, assess potential problems, explore strategic and key stakeholders expectations.

- Program - Reduction of scope will affect the building operational requirements as designed.

Delay - The delay of construction start will impact the anticipated completion and planned student enrollment for Fall quarter of $\mathbf{2 0 1 5 .}$

- Market Conditions - Current economic trend will make future bids less competitive.

- Existing Design and CM firms Capacity of design team to design the project to meet budget is questionable. Competency of CM firm to provide realistic cost estimates is not trustworthy.

> Site Re-considerations - Building the new facility on existing hillside requires massive excavation, expensive labor rates, and materials for retaining walls. The existing parking lot can be considered as alternate site but it is owned by the University Foundation. Additional cost will be options, review the costs and benefits, incurred to compensate the loss of parking spaces. Negotiations with the University Foundation will delay the construction start and final bid result.

Project Delivery System - Exploring other project delivery system such as design-build with revised considerations on project program and budget. This consideration will trigger potential biased opinion on why design-build project delivery was not initially selected.

> Stakeholders' Expectations Managing damage control on private donors' expectations and restoring the university's creditability to deliver the project as originally promised.

\section{Strategic Option 1: Re-bidding with} Current Drawings

This option calls for terminating the existing CM firm from the current CMR contract for convenience as allowed by the CMR model. The current construction drawings will be re-bid using a "hard bid" contracting Design-bidbuild (DBB) delivery system. The freestanding 2,500 SF commons building will be specified as a deductive alternate. The use of alternate provides the building owner an option to delete the commons building if the final base bid exceeds the $\$ 7.8 \mathrm{M}$ construction budget. The re-bid process will take a few months and delay the construction start. The building owner will have little control on numbers of new prospective bidders in the open and competitive DBB model. The selected bidder will have no pre-established relationship with the project team and working knowledge on the project. Also, the selected bidder will look for opportunities on any design deficiencies to offset the low profit margin in a hard-bid environment. There is no guarantee that the re-bid outcome will meet the $\$ 7.8$ $M$ construction budget in light of the current improving economic conditions and bidding market. 
Strategic Option 2: CM's Paying for Redesign with Reprogramming This option engages the same design and $C M$ teams to redesign the entire project. The redesign will require reprogramming for possible reduced scope. There are uncertainties in the project outcome in terms of how the redesign will impact design quality, building finishes and systems. Under the CMR model (CSU Request for Proposal CMR, 2013); the existing CM firm pays for the total redesign efforts because the bid result exceeds the $5 \%$ of the construction budget. However, this option will create potential hostile and legally challenging environment for all parties: the building owner, CM firm, and design team because of substantial redesign fees and other associated expenditure. It will also delay completion of project for a few years due to redesign and agency review processes. The building owner will not have the full project financial capacity because of expanded expenditure as sink cost. The option is not politically feasible because future delays and uncertainties on project outcome will not meet the private donors' expectations. This option serves to punish both the design and CM firms for not directly fulfilling the budgetary and scope requirements. Potential contractual or legal disputes from the design and CM firms will further delay the project.

Strategic Option 3: Redesigning with a new Project Team/Project Delivery Method

This option reviews the possibility of redesigning the entire project with a new design/CM team and a new project delivery system: Design-build (DB). DB delivery allows for design-builder in one single contract. The building owner will demand a highly efficient building layout and configuration with re-programming and site change considerations. The DB delivery will have a potential lower unit construction cost that is contingent on relocating the new buildings off the hillside location to the existing parking lot. It requires negotiation with the University Foundation who owns the parking lot. The current project sink cost is not recoverable and additional funding will be used to compensate for the loss of University Foundation's parking space. There is also uncertainty in achieving total program and budget expectations due to the potential 2-3 year delay in project completion and cost escalation.

\section{Strategic Option 4 - Proceeding with} Current CMR Delivery with Reduced Scope

This option proposes to award the GMP contract to the current CM firm without the commons building of $2,500 \mathrm{SF}$ (Figure 13). To mitigate private donors' concerns on reduced commons space, the building owner can explore the option of re-purposing some of the academic building layout to shared commons space. There will be minor impact to completion date but the construction budget of $\$ 7.8 \mathrm{M}$ will be met. This will maintain the confidence level on predicating the sustainable outcome: reduction of scope through re-purposing and relocation of programming spaces. The intent is to bring the costs down to meet the construction budget without delaying the project completion date. This option has addressed the overall impacts of current challenges on budget, time, and scope. It preserves the integrity of the Process without

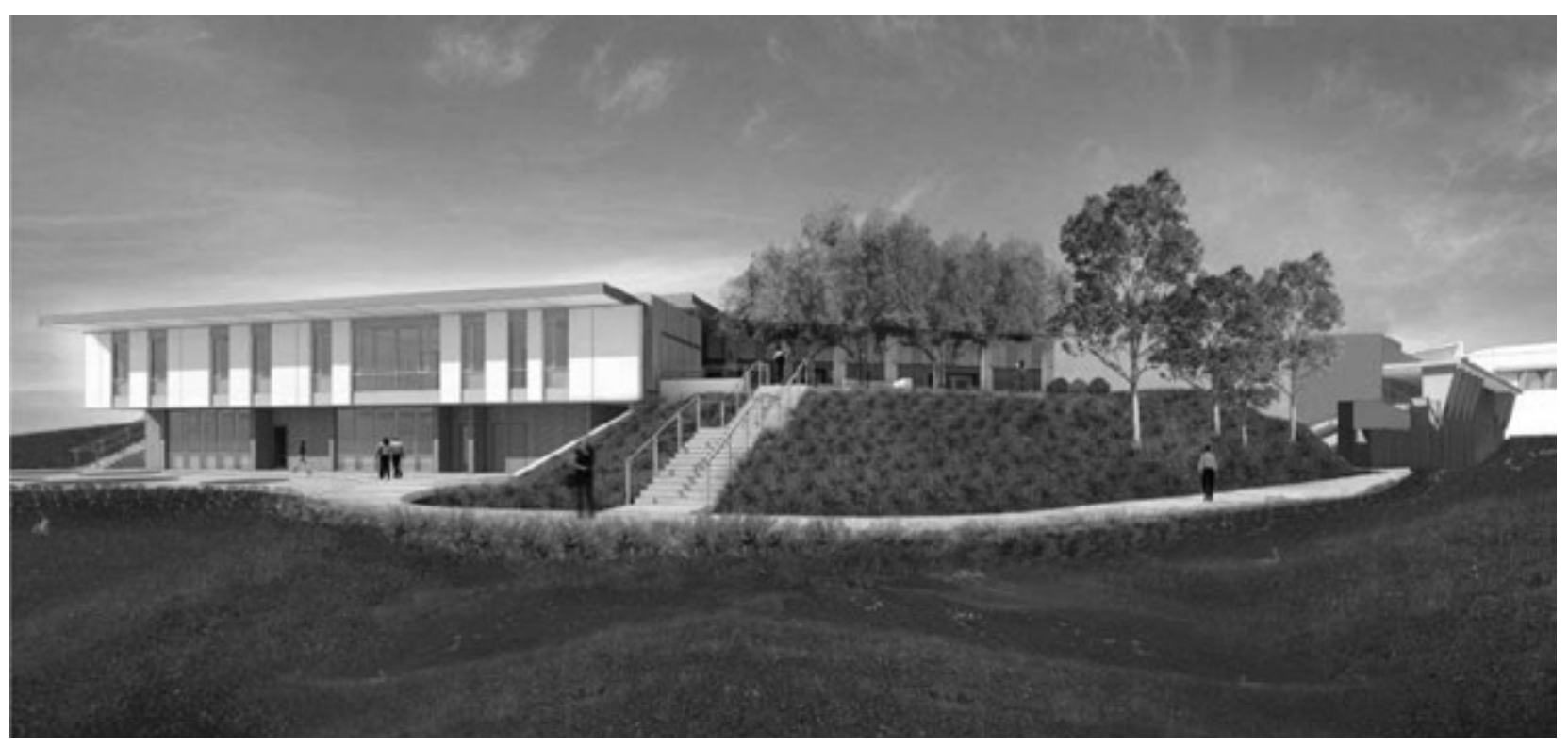

Figure 13 Strategic Option 4 showing deletion of one commons building

Source: Facilities Planning Design \& construction, California State Polytechnic University, Pomona 2014 
compromising the partnering ability of the People to deliver the project. The option also addresses the private donors' expectations that the future of the buildings will be sustained as a project outcome.

\section{Conclusions}

The path to project sustainable outcome starts with the process of how to identify and balance the project constraints to achieve quality results as specified and expected. Shifting roles and responsibilities to the construction managers in early design phase to mitigate owners' exposure to construction risks will not improve the overall project experience and result. Applying an integrated project delivery method is not a substitute for an integrative high performance team. Producing a concise, clear, code compliance, and corrected set of construction drawings is a prerequisite for project success regardless of project delivery system. Exercising the standard of care to ensure the quality of the work for the public health, safety, and well-being is a code of conduct for the project team. In summary, the iterative and collaborative nature of the Process, People and System produces positive project outcome (Figure 7). Applying the right project delivery method is not adequate for achieving project sustainable outcome.
The core effects of Process, People, and System are Efficiency, Satisfaction, and Ethics that form the primary foundation for project sustainable outcome development. Process allows People to collaborate to meet stakeholders' expectations. People interact with System for conformance of requirements. System provides the framework for Process on the consideration of well-being and ethics. When the Process, People, and System interact one other, they activate and produce new improvement opportunities for continuous Collaboration, Conformance, and Consideration (Figure 7) within their core components of Coordination, Implementation, and Alignment. This iterative and continuous flow of interaction provides the check and balance dynamics for better project outcome. The interdisciplinary interaction of continuously balancing project constraints (cost, time, and scope) with the integrative nature of Process, People, and System will contribute to the project sustainable outcome in the built environment (Figure 14). The sustainable outcome occurs in the area where the Process, People, System overlap with the activities of Coordination, Implementation, and Alignment, through collaboration, conformance, and consideration.

\section{References}

American Institute of Architects (AIA 2014). "Primer on Project Delivery", Contributed by the Joint Committee of the AIA and the AGC (May 2013). Retrieved from: http://www.aia. org $/ \mathrm{pdf} /$ dname $=\mathrm{AIAB} 100769$

Association of California Construction Managers (ACCM 2011). "Construction Management Handbook." Retrieved from: http://www. accm.com/documents/ACCMHandbook 20112014edit.pdf

Association for Project Management (APM 2014). "What Is PM", Retrieved from: http://www. apm.org.uk/WhatlsPM

Besner, C., \& Hobbs, B. (2008). Discriminating contexts and project management best practices on innovative and non-innovative projects. Project Management Journal, 39, S123-134.

Ballard, G. (1999). “Improving work flow reliability." 7th International Group for Lean

Construction, Conference, International Group for Lean Construction, Blacksburg, VA, 275-286.

California State University Request for Proposal (2013). Retrieved from:

http://www.calstate.edu/cpdc/CM/cm_at_risk/ cmr_model_ch_i_overview_information_for universities.pdf

Construction Industry Institute (CII 2014). Glossary, Retrieved from https://www. construction-institute.org/scriptcontent/ glossary.cfmsectionOrders.

Construction Management Association of America (CMAA 2011). Owners Guide to Construction and Program Management (2011). Retrieved from: http://www.cmaa.org
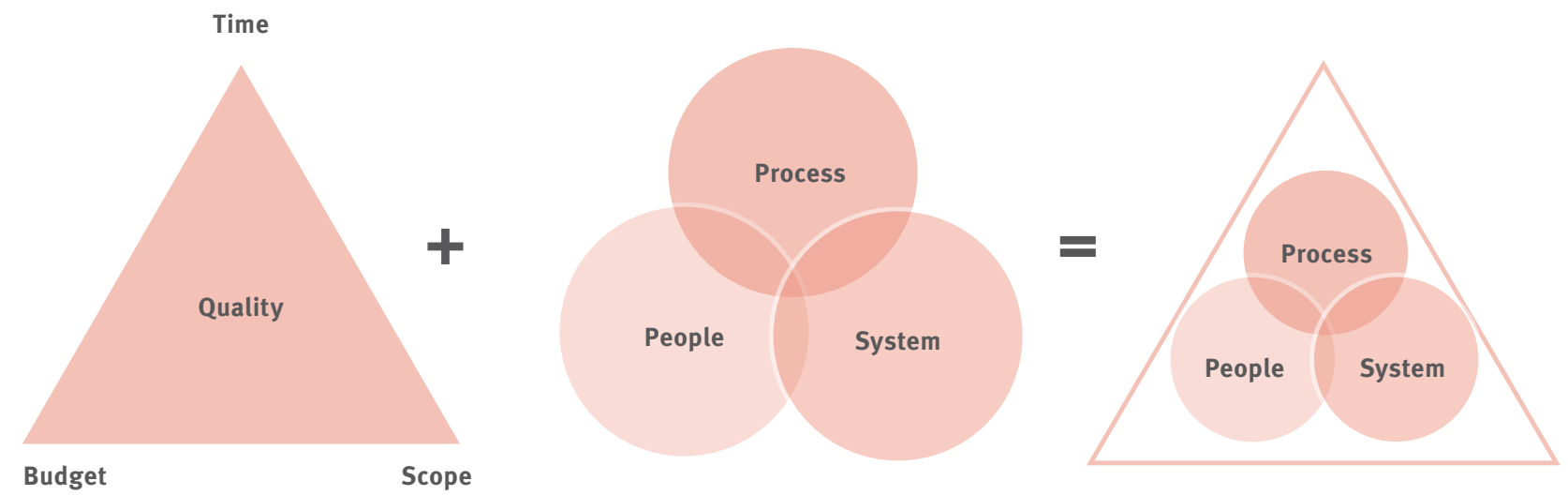
Construction Management Association of America (CMAA 2011). Owners Guide to Project Delivery Methods (2011). Retrieved from: http:www.cmaa.org

Construction Management Association of America (CMAA 2012). Capstone: The History of Construction management Practice and Procedures, 2011.

Design Build Institute of America (DBIA 2013). Intelligence Confidential Report,

Environmental Protection Agency (EPA), “Environmental Impact Assessment” (2008)

Design Build Institute of America (DBIA 2014). What-is-Design-Build, Retrieved from: http:// www.dbia.org/about/Pages/What-is-DesignBuild.aspx.

Gao, T., Ergan, S., Akinci, B., and Garrett, J., (2013), Proactive Productivity Management at Job Sites: Understanding Characteristics of Assumptions Made for Construction Processes during Planning Based on Case Studies and Interviews. Journal of Construction Engineering Management, 140.

Korkmaz, S., Riley, D., and Horman, M. (2010). "Piloting Evaluation Metrics for Sustainable, High Performance Building Project Delivery," ASCE Journal of Construction Engineering and Management.

Lapinski, A., Horman, M., and Riley, D. (2006). "Lean Processes for Sustainable Project Delivery.” J. Constr. Eng. Manage., 132(10), 1083-1091.

Lean Processes for Sustainable Project Delivery Chartered Institute of Building (CIOB), http:// www.ciob.org/redefining-constructionmanagement.

Migliaccio, G.C., G.E. Gibson, and J.T. O'Connor (2008) "Changing Project Delivery Strategy, an Implementation Framework," Public Works Management \& Policy, Vol. 12 No. 3 , pp. 483-502.

Office of the Chancellor, California State University (July 2014). Contract General Conditions (CGC) for the Construction Manager at Risk (CMR) with Guaranteed Maximum Price Projects (Capital Planning, Design and Construction. Retrieved from: http://www.calstate.edu/cpdc/cm

Paul Hawken (1993). The Ecology of Commerce. A Declaration of Sustainability, HarperCollins, 1993, 250 pages

Project Management Institute (PMI 2014) “A Guide to Project Management Body of Knowledge" (PMBOK Guide, 5 th edition,
2013). Retrieved from: http:www.pmi.org

Reed Construction Data/RS Means Market Intelligence Report (2012)

Research Rpeort of the Charles Pankow Foundation and DBIA Charles Pankow Foundation (Nov 2010) Influence of Project Delivery on Sustainable, High Performance Building.

Sanvido, V., and Konchar, M. (1998). Project delivery systems: CM at risk, DB, DBB, CII

The Work Bank, Sustainable Development (2014). Retrieved from: http://www.worldbank.org/ en/topic/sustainabledevelopment.

Thomas, H. R., Horman, M. J., Minchin, R. E. Jr., and Chen, D. (2003). "Improving labor flow reliability for better productivity as lean construction principle." Journal of Construction Engineering Management, 10.1061/(ASCE) 0733-9364(2003)129:3(251), 251-261.

United Nations General Assembly Resolution Report of the World Commission on Environmental \& Development (1987).

Zaghloul, R., and Hartman, F. (2003). "Construction Contracts: The Cost of Mistrust.” International Journal of Project Management, 21(6), 419-424 